\title{
Early detection of thymidylate synthase resistance in non-small cell lung cancer with FLT-PET imaging
}

\author{
Xiao Chen ${ }^{1,2}$, Yizeng Yang ${ }^{3}$ and Sharyn Katz ${ }^{1}$ \\ ${ }^{1}$ Department of Radiology, University of Pennsylvania Perelman School of Medicine, Philadelphia, PA, USA \\ ${ }^{2}$ Department of Radiology, Institute of Surgery Research, Daping Hospital, Third Military Medical University, Chongqing, \\ China \\ ${ }^{3}$ Department of Medicine, University of Pennsylvania Perelman School of Medicine, Philadelphia, PA, USA \\ Correspondence to: Sharyn Katz, email: sharyn.katz@uphs.upenn.edu \\ Keywords: FLT, PET, pemetrexed, lung cancer, flare
}

Received: April 19, $2017 \quad$ Accepted: June 01, $2017 \quad$ Published: July 31, 2017

Copyright: Chen et al. This is an open-access article distributed under the terms of the Creative Commons Attribution License 3.0 (CC BY 3.0), which permits unrestricted use, distribution, and reproduction in any medium, provided the original author and source are credited.

\section{ABSTRACT}

Introduction: Inhibition of thymidylate synthase (TS) results in a transient compensatory "flare" in thymidine salvage pathway activity measureable with ${ }^{18}$ F-thymidine (FLT)- positron emission tomography (PET) at 2 hrs. of therapy which may predict non-small cell lung cancer (NSCLC) sensitivity to TS inhibition.

Materials and Methods: Resistance to TS inhibition by pemetrexed was induced in NSCLC cell lines H460 and H1299 through TS overexpression. TS overexpression was confirmed with RT-PCR and Western blotting and pemetrexed resistance confirmed with $\mathrm{IC}_{50}$ assays. The presence of a pemetrexed-induced thymidine salvage pathway "flare" was then measured using ${ }^{3} \mathrm{H}$-thymidine in both pemetrexed sensitive ( $\mathrm{H} 460$ and H1299) and resistant (H460R, H1299R, CALU-6, H522, H650, H661, H820, H1838) lines in vitro, and validated with FLT-PET in vivo using H460 and H460R xenografts.

Results: Overexpression of TS induced pemetrexed resistance with $\mathrm{IC}_{50}$ for $\mathrm{H460}$, H1299, H460R and H1299R measured as 0.141 $\mu M, 0.656 \mu M, 22.842 \mu M, 213.120$ $\mu \mathrm{M}$, respectively. Thymidine salvage pathway ${ }^{3} \mathrm{H}$-thymidine "flare" was observed following pemetrexed in H460 and H1299 but not H460R, H1299R, CALU-6, H522, H650, H661, H820 or H1838 in vitro. Similarly, a FLT "flare" was observed in vivo following pemetrexed therapy in H460 but not H460R tumor-bearing xenografts.

Conclusions: Imaging of TS inhibition is predictive of NSCLC sensitivity to pemetrexed.

\section{INTRODUCTION}

Inhibitors of thymidylate synthase (TS), a key enzyme in the de novo thymidine synthesis pathway, play a role in the treatment of a number of malignancies including non-small cell lung cancer (NSCLC). Examples of commonly used TS inhibitors in cancer therapy include 5-fluorouracil (5-FU), pemetrexed and capecitabine. Successful inhibition of TS results in a transient compensatory "flare" in activity of the thymidine salvage pathway [1-4], which also sources thymidine to the dividing cell. As a result, this drug-induced compensatory "flare" in thymidine salvage pathway activity is an indicator of successful TS inhibition. This drug-induced change in tumor metabolism can be made visible through ${ }^{18} \mathrm{~F}$-thymidine (FLT)-positron emission tomography (PET) $[2,5-7]$, an analog of thymidine. FLT, first described by Shields in 1998 [8], is an investigational imaging biomarker of the thymidine salvage pathway currently in use for human clinical trials primarily as a validated surrogate marker of tumor proliferation [9-12]. Here we consider FLT-PET imaging as a means of detecting successful TS targeting by pemetrexed, a TS inhibitor currently in use for NSCLC therapy. 
In our recent publication [7], we characterized the kinetics of the pemetrexed-induced thymidine salvage pathway "flare" in a xenograft mouse model of human NSCLC and demonstrated that the peak of the pemetrexed-induced thymidine salvage pathway "flare" consistently occurs at 2 hours of exposure to therapy both in vitro and in vivo. Beyond that 2 hour time point, the pemetrexed-induced "flare" signal decays, dissipating entirely by 24 hours of therapy at which time the antiproliferative effects of successful therapy have begun to dominate thymidine salvage pathway activity. We also have determined that the pemetrexed-induced "flare" effect is mediated in part by rapid changes in the activity of thymidine kinase 1 (TK1), the key rate-limiting step in the thymidine salvage pathway enzyme and on the mobilization of equilibrative nucleoside transporter 1 (ENT 1) to the cell surface. ENT1 has been shown to be important for facilitation of thymidine, and thymidine analogues, entry into proliferating cells [13-16]. These findings are consistent with published literature also demonstrating that increases in TK1 activity and/or ENT1 mobilization play a significant role in the TS-inhibition mediated thymidine salvage pathway "flare" in activity [2, 3, 17-19].

The question remains whether this TS inhibitorinduced thymidine salvage pathway "flare" in tumor metabolism can serve as a reliable indicator of therapy success with eventual tumor regression. While there is literature describing the phenomenon the TS-inhibition induced "flare" in the salvage pathway activity, there is very little available data examining whether this strategy can be predictive of drug therapy success in cancer with several published papers yielding mixed results [20, 21]. Therefore careful pre-clinical study is warranted to determine whether the pemetrexed-induced "flare" can be predictive of therapy success in NSCLC. Previously, our laboratory has examined the thymidine salvage pathway "flare" imaging strategy in the setting of pemetrexed sensitivity [7]; we now characterize the "flare" in the setting of pemetrexed resistance. TS overexpression is a common and well-described mechanism of cancer resistance to TS inhibitors including NSCLC resistance to pemetrexed [22-25]. In this study we employ TS overexpression to induce resistance to TS inhibition in order to study the pemetrexed-induced "flare" in thymidine salvage pathway activity in the setting of NSCLC drug resistance.

\section{RESULTS}

\section{Overexpression of TS is associated with resistance to pemetrexed in NSCLC lines in vitro}

Overexpression of TS in H460 and H1299 cell lines was confirmed in vitro using RT-PCR, Western blotting and immunofluorescence (Figure 1 and Supplementary
Figure 1). $\mathrm{IC}_{50}$ measurements confirmed pemetrexed sensitivity in the wild-type H460 and H1299 cell lines and the development of pemetrexed resistance in the TS overexpressing H460R and H1299R cell lines with $\mathrm{IC}_{50}$ measurements of $0.141 \mu \mathrm{M}, 22.8 \mu \mathrm{M}, 0.656 \mu \mathrm{M}, 213$ $\mu \mathrm{M}$ for H460, H460R, H1299 and H1299R respectively (Supplementary Figure 2).

In addition, the TS protein expression was also noted to be elevated in six inherently pemetrexed resistant NSCLC cell lines CALU6, H522, H650, H661, H820, H1838 relative to pemetrexed-sensitive cell lines H460 and H1299 (Supplementary Figure 1) with IC50 measurements of (Supplementary Figure 2). The IC50 for CALU6, H522, H650, H661, H820, H1838 were 14.2, $59.6,238,85.0,48.0,121 \mu \mathrm{M}$ respectively.

\section{Overexpression of TS induces resistance to pemetrexed in NSCLC lines H460 and H1299 in vivo}

Xenografts bearing H460 (16 mice) or H460R (16 mice) were treated as either vehicle only controls (8 mice per cell line) or given combination therapy with pemetrexed and cisplatin ( 8 mice per cell line) for 2 weeks. Routine external caliper tumor measurements were compared between treated and control groups for each cell line. A significant tumor growth inhibition was observed in the pemetrexed-sensitive H460 chemotherapy treated tumors $(74.7 \pm 15.1 \% ; \mathrm{p}=0.0002)$ relative to untreated vehicle only controls. There was a slight tumor growth inhibition in the treated pemetrexed-resistant H460R tumors when compared to vehicle only treated controls (47.8 $\pm 14.4 \%, \mathrm{p}=0.0001)$ (Supplementary Figure 3).

\section{Induction of pemetrexed resistance through TS overexpression results in loss of thymidine salvage pathway "flare" in vitro}

Thymidine salvage pathway activity was assayed with ${ }^{3} \mathrm{H}$-thymidine at baseline and following treatment with either pemetrexed, cisplatin or combination of cisplatin and pemetrexed in vitro. A "flare" in thymidine salvage pathway activity measured in pemetrexedsensitive NSCLC lines H460 (43.4 $\pm 5.11 \%, \mathrm{p}=0.0005)$ and $\mathrm{H} 1299(39.5 \pm 6.51 \%, \mathrm{p}<0.0001)$ but not in TS overexpressed pemetrexed-resistant NSCLC cell lines H460R $(-2.44 \pm 0.95 \%, p=0.421)$ and H1299R $(-0.60 \pm 4.40 \%, \mathrm{p}=0.870)$ in vitro using ${ }^{3} \mathrm{H}$-thymidine assays (Figure 2). In addition, none of the six lines inherently NSCLC resistant NSCLC cells had a pemetrexed-induced thymidine salvage pathway "flare" at 2 hours (CALU6: $-1.87 \pm 7.20 \%, \mathrm{p}=0.742 ; \mathrm{H} 522: 7.63 \pm 6.00 \%, \mathrm{p}=0.115$; H650: $-1.73 \pm 3.99 \%, \mathrm{p}=0.454$; H661: $3.82 \pm 5.13 \%$, $\mathrm{p}=0.201 ; \quad \mathrm{H} 820: \quad-0.03 \pm 3.37 \%, \quad \mathrm{p}=0.958 ; \quad \mathrm{H} 1838$ : $3.21 \pm 5.20 \%, \mathrm{p}=0.250$ ) (Figure 3). One cell line, CALU6, 
had a delayed "flare" at 24 hours following start of exposure to pemetrexed therapy $(66.9 \pm 8.08 \%, \mathrm{p}=0.0005)$.

\section{Induction of pemetrexed resistance through TS overexpression results in loss of thymidine salvage "flare" in vivo}

A total of 4 groups of xenografted mice were imaged with FLT-PET at baseline and at 2 hours of therapy and changes in tumor avidity for FLT were measured. These groups were as follows: H460 (8 mice; vehicle only), H460R (8 mice; vehicle only), H460 (8 mice; cisplatin/pemetrexed), H460R (8 mice; cisplatin/ pemetrexed). A FLT "flare" in tumor avidity was observed at 2 hours of therapy for pemetrexed-sensitive H460 xenografts $(58.6 \pm 16.1 \%$ increase over baseline; $\mathrm{p}=0.043$ ) but not pemetrexed-resistant H460R xenografts (10.8 $\pm 7.28 \%$ increase over baseline; $p=0.653$ )
(Figure 4). No FLT "flare" was observed in the vehicleonly controls for $\mathrm{H} 460$ (1.44 $\pm 6.35 \%$ increase over baseline; $\mathrm{p}=0.9582)$ or H460R $(2.34 \pm 11.86 \%$ increase over baseline ; $\mathrm{p}=0.9527$ ).

\section{DISCUSSION}

Tumor resistance to pemetrexed, a TS inhibitor used in the treatment of NSCLC, is a common problem in oncologic management. Successful TS inhibition results in a transient "flare" in tumor cellular thymidine salvage pathway activity that is measurable in vitro and in vivo with FLT-PET imaging. In a previous publication, we described the optimal timing of imaging the TS-inhibition mediated "flare" in the thymidine salvage pathway and detailed mechanisms underlying this effect including increasing of TK1 activity and mobilization of ENT1 to

\section{Thymidylate Synthase Expression}

a. Immunofluorescence
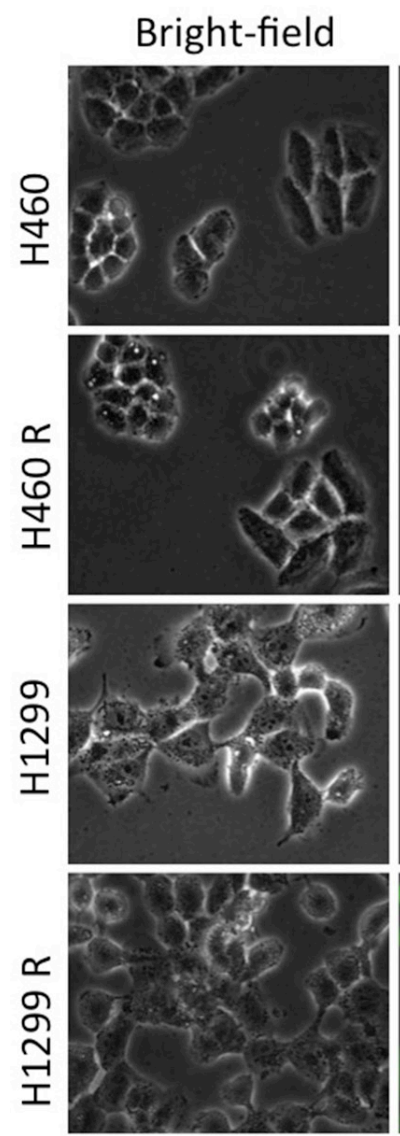
Fluorescence
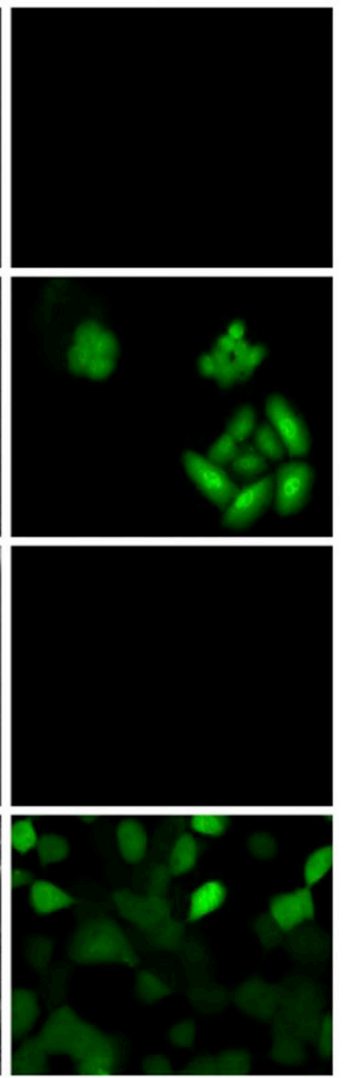

b.

RT-PCR

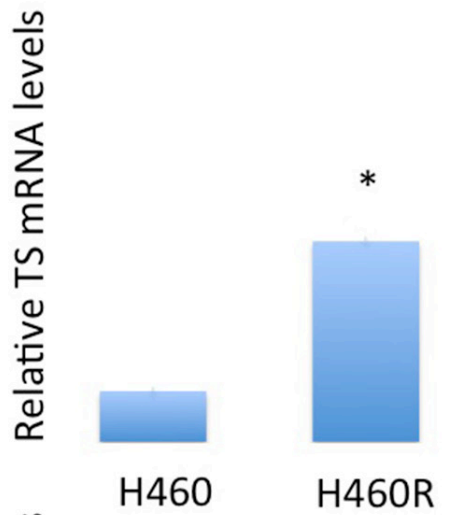

$*$

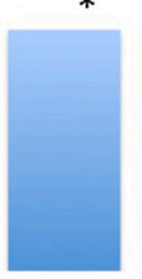

H1299 c.

Western

TS
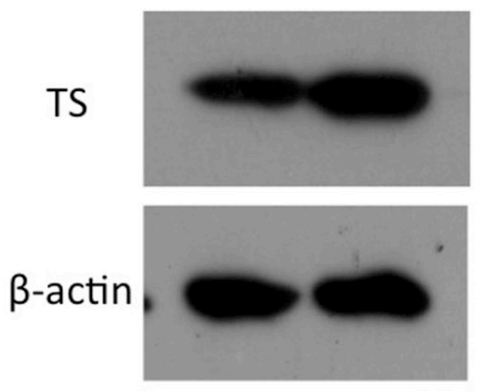

H460 H460R

TS

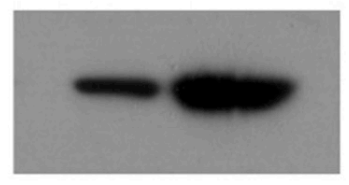

$\beta$-actin

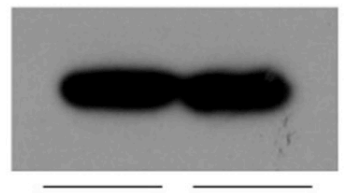

H1299 H1299R

Figure 1: Overexpression of thymidylate synthase in NSCLC cell lines H460 and H1299. Pemetrexed sensitive human NSCLC cell lines H460 and H1299 expressed thymidylate synthase (TS) at low levels at baseline. Overexpression of TS in both cell lines, termed H460R and H1299R, was confirmed with (a) detection of GFP in transfected cells by immunofluorescence (TS), (b) quantification of TS mRNA by RT-PCR and (c) protein expression. 
the cell surface [7]. In this study we further examine this imaging technique to determine if the presence of the TS-inhibition induced "flare" in the thymidine salvage pathway is predictive of NSCLC tumor sensitivity to pemetrexed.

Since overexpression of TS is a common mechanism of tumor resistance to TS-inhibition, we chose to study the impact of pemetrexed resistance on the thymidine salvage pathway "flare" by overexpressing TS in two previously sensitive NSCLC cell lines, H460 and H1299. All examined pemetrexed-resistant NSCLC cell lines, those created though overexpression of TS and inherently resistant cell lines, demonstrated elevated levels of TS protein expression relative to the pemetrexed sensitive NSCLC cell lines, H460 and H1299. This is in keeping with published literature demonstrating that TS overexpression is a common mechanism for resistance to pemetrexed therapy in NSCLC [22].
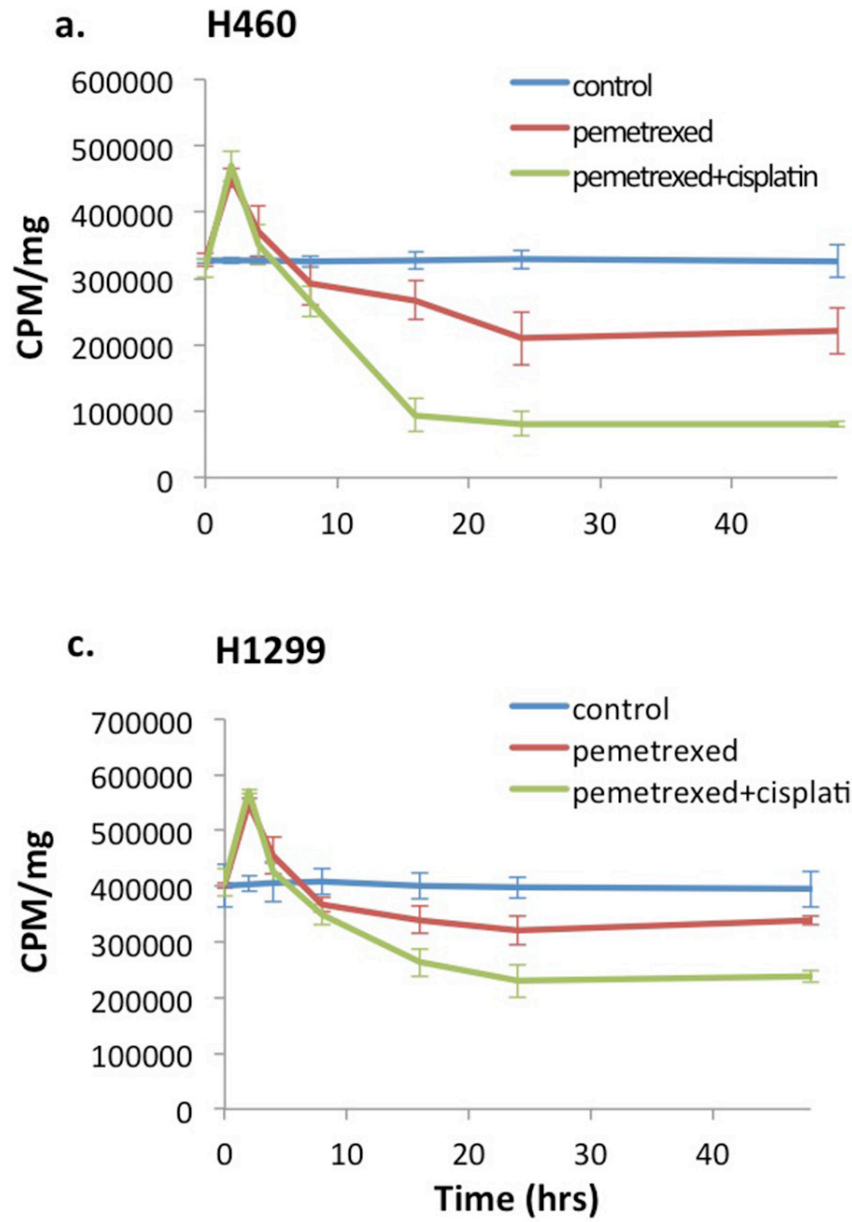

Following overexpression of TS, H460R and H1299R cell lines demonstrated the expected resistance to treatment with pemetrexed as measured by $\mathrm{IC}_{50}$ assays in vitro and relative tumor growth inhibition in vivo. The pemetrexed-resistant H460R xenografts still demonstrated some tumor growth inhibition in response to chemotherapy as a result of sensitivity to cisplatin. Combination therapy with cisplatin and pemetrexed therapy was administered in order to model the regimen typically administered to NSCLC patients. Even so, the absence of thymidine salvage pathway FLT-PET "flare" in vivo was able to correctly identify tumors exhibiting a suboptimal tumor response to therapy due to pemetrexed resistance.

Two pemetrexed-sensitive human NSCLC cell lines, H460 and H1299, both exhibit a TS-inhibition mediated thymidine salvage pathway flare at 2 hours of exposure to pemetrexed. With induction of pemetrexed-resistance through TS overexpression, both H460R and H1299R cell lines reveal a loss of the TS-inhibition mediated thymidine

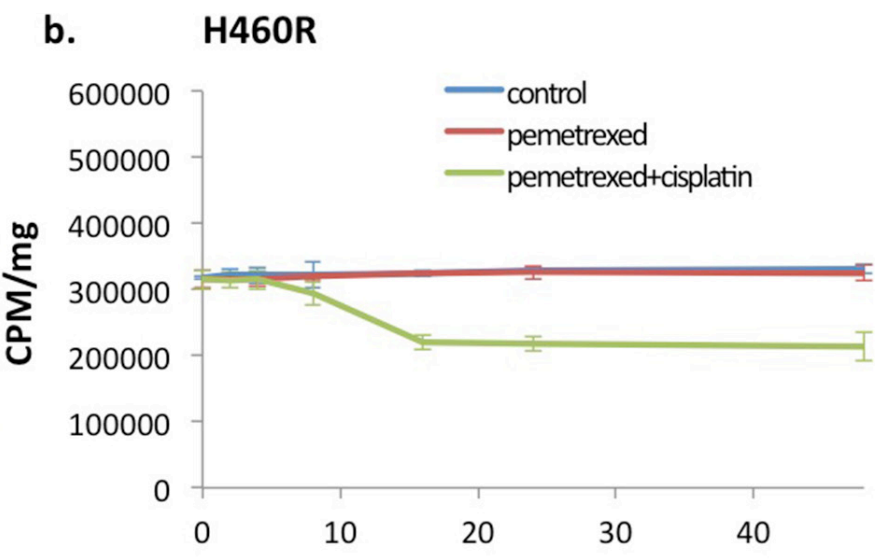

d. H1299R

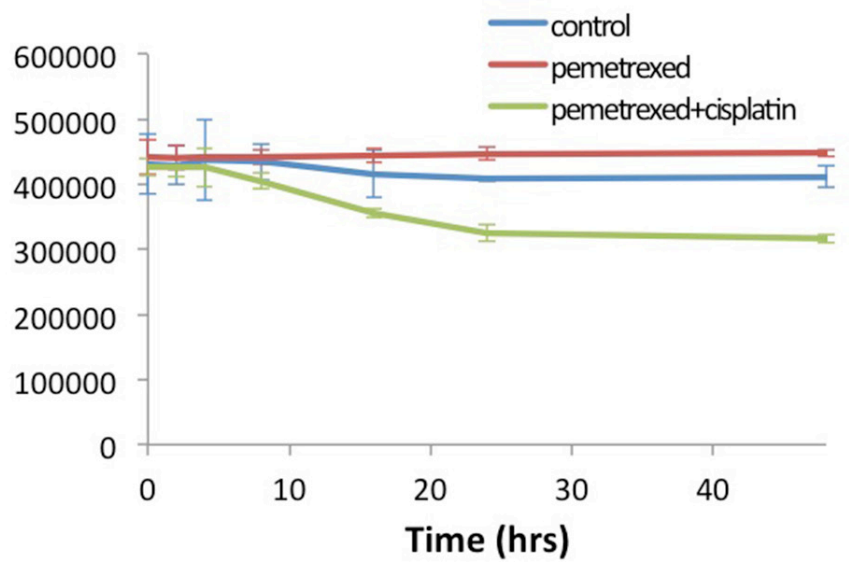

Figure 2: Pemetrexed-resistance conferred by TS overexpression results in loss of the pemetrexed-induced DNA salvage pathway "flare" in NSCLC in vitro. Pemetrexed-sensitive wild type NSCLC cell lines H460 (a) and H1299 (c) demonstrated a "flare" in thymidine salvage pathway on $3 \mathrm{H}$-thymidine assay at $2 \mathrm{hrs}$. of exposure to pemetrexed. The overexpression of TS eliminated the pemetrexed-induced "flare" in thymidine salvage pathway activity in both cell lines, H460R (b) and H1299R (d). The exposure to cisplatin did not impact the presence of the pemetrexed-induced thymidine salvage pathway "flare". 

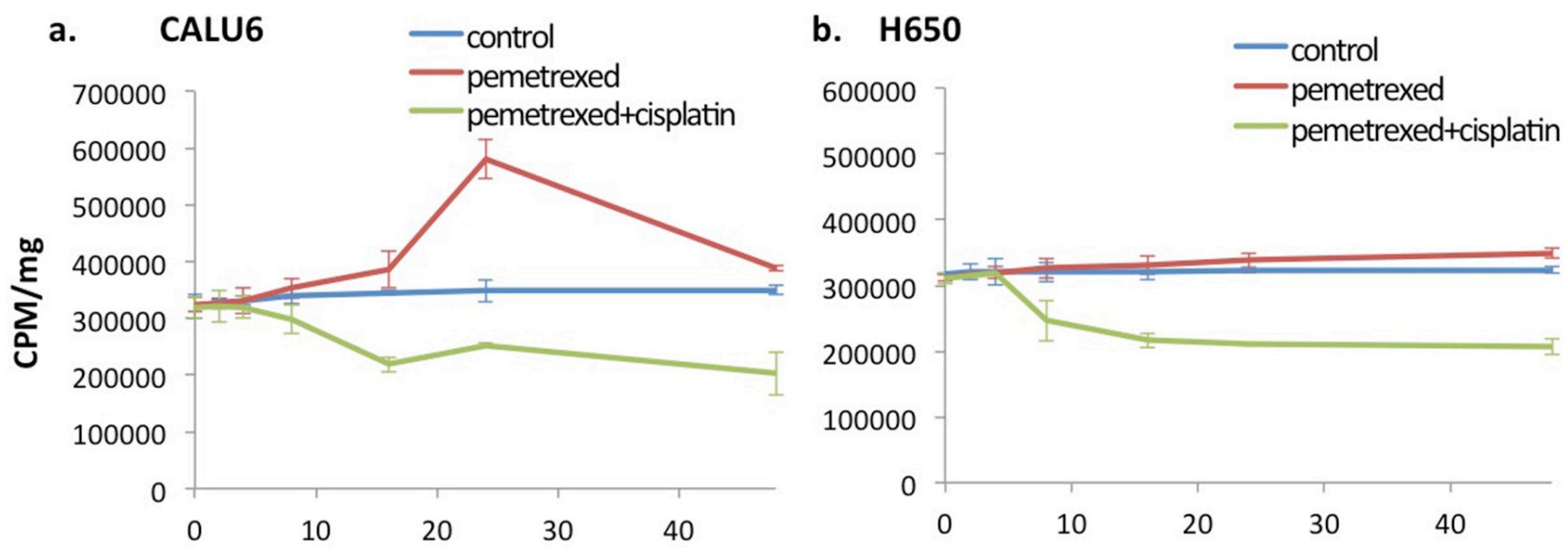

\section{c. $\mathrm{H} 820$}
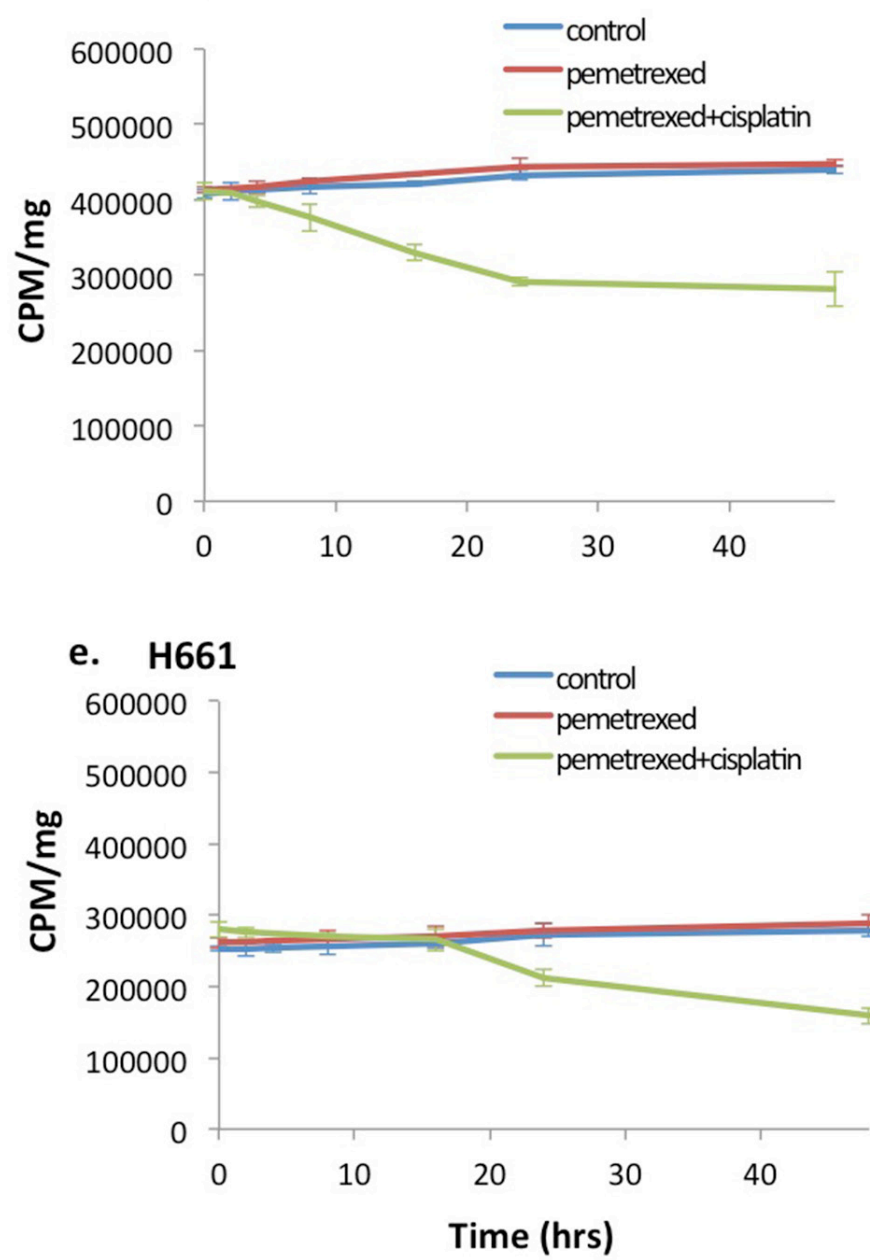

d. $\quad \mathrm{H} 1838$

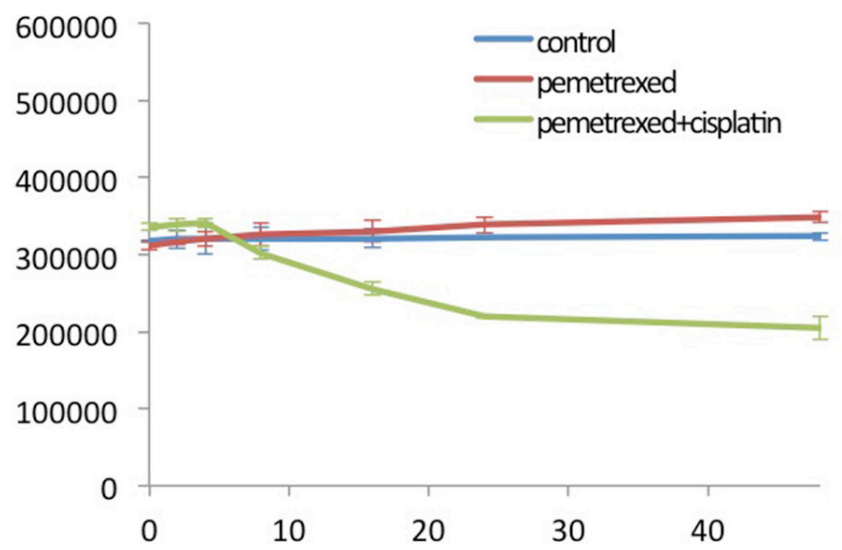

f. $\quad$ H522

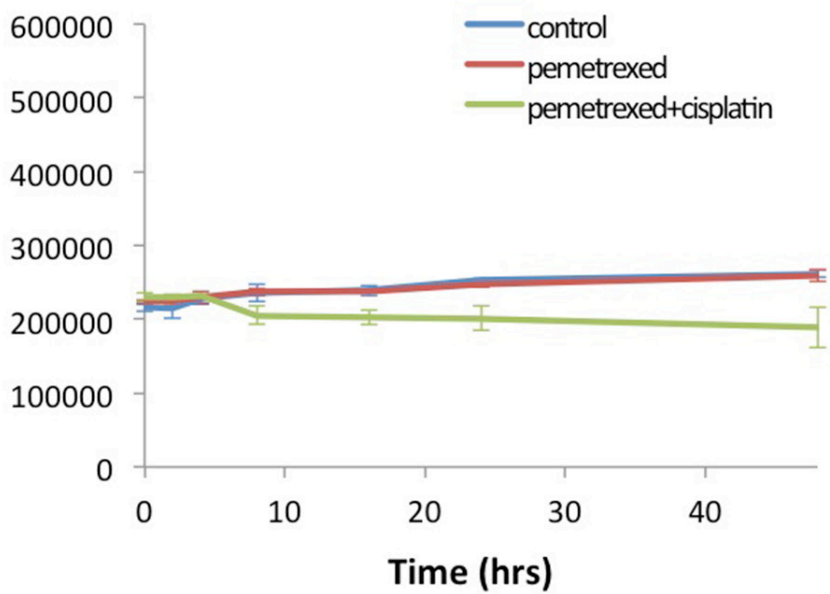

Figure 3: Wild-type resistance to pemetrexed in NSCLC cell lines results in loss of the thymidine salvage pathway induced "flare" at the $\mathbf{2} \mathbf{h r}$ time point. $3 \mathrm{H}$-thymidine assay was performed on inherently pemetrexed-resistant NSCLC cell lines (a-f) following incubation without chemotherapy (culture medium only), pemetrexed $(100 \mathrm{nM})$ or combination therapy with pemetrexed (100 nM) plus cisplatin $(10 \mathrm{mM})$. No "flare" in thymidine salvage pathway activity was seen at $2 \mathrm{hrs}$. of exposure to pemetrexed in any of the 6 pemetrexed-resistant cell lines. One cell line, CALU6 (a), demonstrated a delayed increase in thymidine pathway activity occurring at approximately 24 hrs. of therapy. Exposure to cisplatin showed no impact on the pemetrexed induced "flare". 
salvage pathway "flare" at 2 hours in vitro and in vivo. This loss of the thymidine salvage pathway "flare" was also observed in a panel of inherently pemetrexed-resistant wild-type NSCLC cell lines. Interesting, one of these resistant cell lines, CALU-6, exhibited a delayed increase in thymidine salvage pathway at 24 hours of exposure to therapy. We hypothesize that this delayed increased in thymidine salvage pathway activity at 24 hours may be on the basis of TS-inhibitor-induced increased expression of TK1 as previously reported [2]. It should be noted that in this study we did not folate restrict the murine diet or administer intravenous thymidine phosphorylase prior to imaging, which is sometimes done to prevent saturation of TS or FLT by high murine endogenous levels of folate or thymidine respectively. As a result, our data may underestimate the magnitude of the pemetrexed induced FLT "flare" in NSCLC.

In summary, here we demonstrate evidence that the presence of a thymidine salvage pathway "flare" at 2 hours may be predictive of tumor response to pemetrexed therapy in a preclinical model of human NSCLC. In this study we demonstrated the absence of a TS-inhibition induced "flare" in thymidine salvage pathway activity in all of the 8 pemetrexed-resistant NSCLC cell lines. The data presented here is complementary to our previous report demonstrating the presence of a TS-inhibition mediated thymidine salvage pathway "flare" at 2 hours in all of the 8 pemetrexed-sensitive human NSCLC cell lines examined. Although there is a published clinical pilot study of the FLT "flare" in NSCLC which did not demonstrate a predictive value of this technique [20], it is plausible that other variables such as concurrent treatment with dexamethasone, known to decrease the expression of thymidylate synthase and dihydrofolate reductase and impact tumor responsiveness to pemetrexed [26], could impact the translation of this technique into the clinic. Careful study is needed to determine if the TS-inhibition mediated FLT "flare" could be of value in the clinical setting. If successful, this technique has the potential of

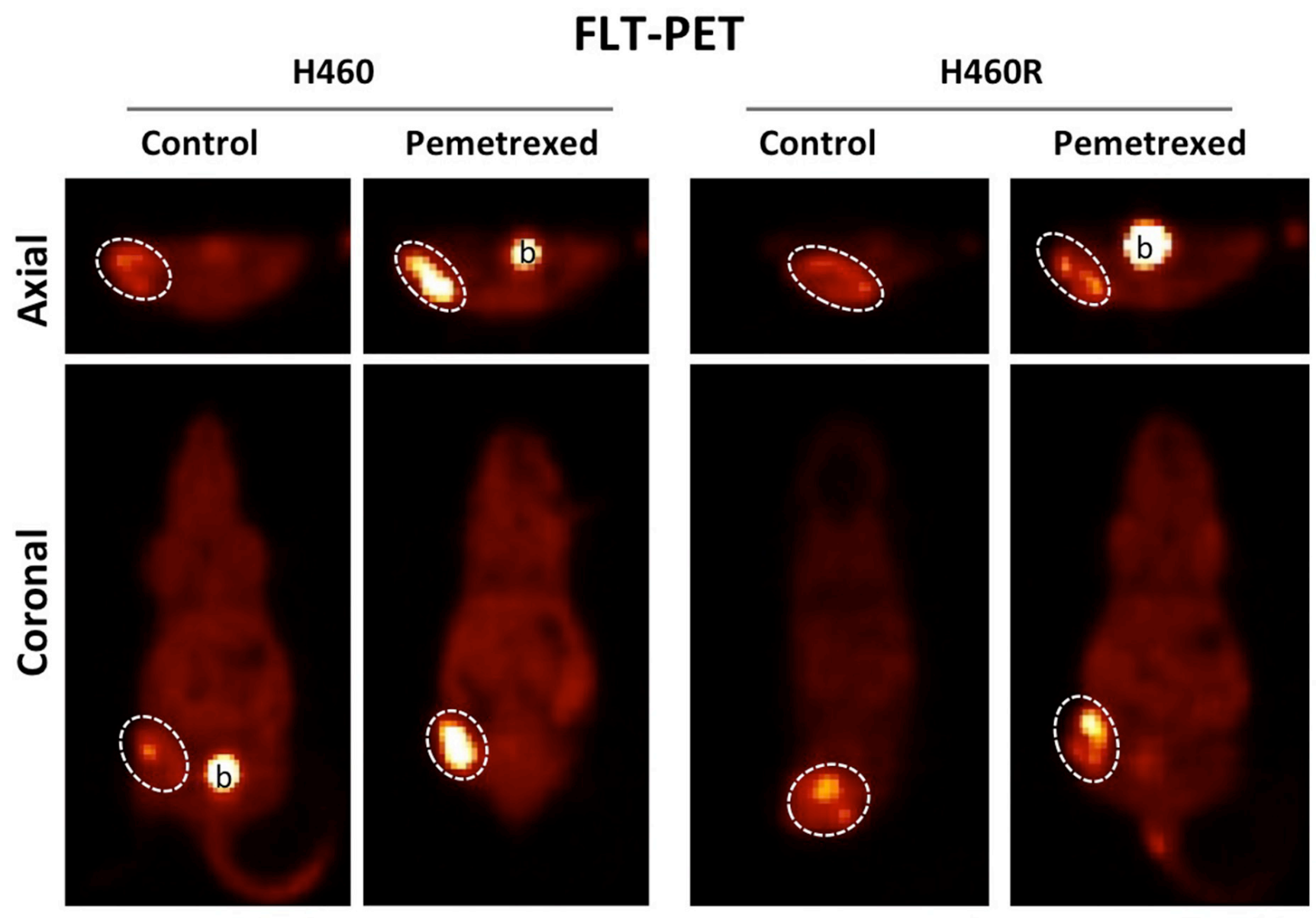

Figure 4: Pemetrexed-resistance conferred by TS overexpression results in loss of the pemetrexed-induced thymidine salvage pathway "flare" in NSCLC in vivo. FLT-PET imaging was performed on pemetrexed-sensitive H460 and pemetrexedresistant H460R xenografts the day before and 2 hours after exposure to combination therapy with pemetrexed and cisplatin. A pemetrexedinduced "flare" in thymidine salvage pathway activity is observed in the pemetrexed sensitive H460 xenografts but not the resistant H460R xenografts. 
determining NSCLC sensitivity to pemetrexed therapy as early as the day of therapy start.

\section{MATERIALS AND METHODS}

\section{Chemotherapeutics and imaging radiopharmaceuticals}

For in vitro studies, pemetrexed (Santa Cruz Biotechnology, Dallas, Texas) and cisplatin (SigmaAldrich Corp., St. Louis, MO) were provided in solid form, dissolved in water and stored at $-20^{\circ} \mathrm{C}$ as a 0.2 $\mathrm{mM}$ and $1 \mathrm{mM}$ stock, respectively. For in vivo use, both human and murine, pemetrexed (ALIMTA; Eli Lilly and Company, Indianapolis, IN) and cisplatin (Teva Pharmaceuticals, PetachTikva Israel) were provided freshly prepared as a $1 \mathrm{mg} / \mathrm{ml}$ sterile saline solution by the Abramson Cancer Center Pharmacy. For in vivo murine studies, chemotherapeutics were stored at $4{ }^{\circ} \mathrm{C} .\left[{ }^{18} \mathrm{~F}\right] \mathrm{FLT}$ was produced on site in the University of Pennsylvania PET Center Cyclotron facility. $\left[{ }^{18} \mathrm{~F}\right] \mathrm{FLT}$ average specific activity was $5.32+/-2.14 \mathrm{Ci} / \mathrm{umol}$, and radiochemical purity $>99 \%$.

\section{Cell lines and culture}

All human non-small cell lung cancer cell lines were obtained from American Type Culture Collection (ATCC, Manassas, VA). Both cell lines were grown in RPMI medium containing 10\% fetal bovine serum (FBS), $100 \mathrm{IU} / \mathrm{mL}$ penicillin, and $100 \mu \mathrm{g} / \mathrm{mL}$ streptomycin in a humidified incubator in $5 \% \mathrm{CO} 2$ at $37^{\circ} \mathrm{C}$. Passage of cell lines was performed at 1:3 dilution after detachment using sterile $0.05 \%$ trypsin-EDTA solution.

\section{$\mathrm{IC}_{50}$ calculations}

Cultured cell lines were harvested and seeded into a 24-well plate $\left(2 \mathrm{X} 10^{4}\right.$ cells per well) in RPMI 1640 culture medium and incubated for 24 hours at $37^{\circ} \mathrm{C}$ in a $5 \% \mathrm{CO}_{2}$ incubator. The culture medium was then replaced with 100 $\mathrm{uL}$ of fresh medium containing varying concentrations of pemetrexed $(0,0.01,0.1,1,10,100 \mu \mathrm{M})$ and incubated for 72 hours at $37^{\circ} \mathrm{C}$ in a $5 \% \mathrm{CO}_{2}$ incubator. The $\mathrm{IC}_{50}$ assay was performed then performed using the MTT Cell Growth Assay Kit (Sigma-Aldrich, St. Louis, MO). Absorbance of the converted dye was measured using a Beckman DU-600 Spectrophotometer (Beckman Coulter Life Sciences, Indianapolis, IN) and data analyzed using the statistical software SPSS 19.0 (IBM, Chicago, USA).

\section{Mouse tumor xenograft modeling}

Prior to in vivo animal modeling, approval was obtained by the Institutional Animal Care and Use Committee (IACUC) at the University of Pennsylvania.
Human tumor-bearing murine xenografts were then created using two month-old female $n u / n u$ mice $(\mathrm{Crl}$ : NUFoxnlnu, Charles River Laboratory, Wilmington, MA) and fed a conventional murine diet. Each mouse was injected subcutaneously in the flank with a suspension of H460 cells $\left(5 \times 10^{6}\right)$ in sterile, endotoxin-free $50 \%$ Matrigel Matrix (Corning Inc., Corning, NY). When tumors reached a mean volume of approximately $200 \mathrm{~mm}^{3}$ (volume $=\pi / 6$ $\times$ length $\times$ width $\times$ height), animals were randomized into treatment groups.

\section{${ }^{3} \mathrm{H}$-thymidine assays}

$\left[{ }^{3} \mathrm{H}\right]$-thymidine (Perkin Elmer NET355001MC, PerkinElmer, Waltham, MA) was utilized for in vitro assessment of therapy-induced changes in thymidine salvage pathway activity in cultured human NSCLC cells. $\left[{ }^{3} \mathrm{H}\right]$-thymidine specific activity was $>10 \mathrm{Ci}(370 \mathrm{GBq}) /$ mmol and radiochemical purity $>97 \%$. H460 and H1299 cells were seeded $\left(1 \times 10^{6} /\right.$ well $)$ in 6-well plate in RPMI1640 supplemented with 10\% FBS and antibiotics, incubated 24 hours in $5 \% \mathrm{CO}_{2}$ at $37^{\circ} \mathrm{C}$. When cell cultures achieved $80 \%$ confluence, cells were exposed to treatment with either the vehicle (sterile water), pemetrexed (100 $\mathrm{nM})$, or the combination of pemetrexed $(100 \mathrm{nM})$ and cisplatin $(10 \mu \mathrm{M})$ in growth media for varying exposure times ranging up to 48 hours. Drug-containing medium was then removed, and the cells were then washed and pulsed with $5 \mu \mathrm{Ci}\left[{ }^{3} \mathrm{H}\right]$-thymidine/well for 1 hour. The cells were then washed and scraped into plastic vials. Scintillant (10 mL; Research Products International Corp., Mount Prospect, IL) was added to each vial and the radioactivity was counted on a scintillation counter (Beckman Coulter LS6500, Beckman Coulter Life Sciences, Indianapolis, IN).

\section{Gene overexpression}

A full-length cDNA fragment encoding TS was obtained from pDONR223-DTYMK plasmid (Addgene) by polymerase chain reaction with the primers TS-F (5'-ATCCCGGGCCTTGAGCGGCCCGGCGCGGG-3') and TS-R (5'-CTCCGGAACGAATTCTCACTTCCA TAGCTC-3'), and subcloned into the Xbal and EcoR I sites of lentiviral vector pUltra (Addgene). The product was verified by sequencing. Lentivirus was packaged by transfecting into HEK 293T cells with the packaging plasmids pMD2-VSV.G and pCMV-dR8.74. Viruscontaining medium was harvested 48 hours and 72 hours after transfection and filtered with $0.45 \mu \mathrm{m}$ Millex HV filters (EMD Millipore). Lenti-X Concentrator (Clontech) and virus-containing medium (v/v: 1:3) were mixed and incubated at $4{ }^{\circ} \mathrm{C}$ for 1 hour. The viral particles were concentrated by centrifugation at $1,500 \mathrm{x}$ g for 45 minutes at $4^{\circ} \mathrm{C}$. The resulting pellet was then suspended in fresh 
RPMI 1640 medium and used to infect H460 and H1299 cells.

\section{Immunoblotting}

Therapy-induced changes in the protein expression of key components of the thymidine salvage pathway were assessed using Western blot analysis. H460 and H1299 cells were seeded $\left(1 \times 10^{6}\right.$ cells/well $)$ in 6-well plate in RPMI1640 supplemented with 10\% FBS and antibiotics, incubated 24 hour in $5 \% \mathrm{CO}_{2}$ at $37^{\circ} \mathrm{C}$. When cell cultures achieved $80 \%$ confluence, cells were exposed to treatment with either the vehicle (sterile water), pemetrexed (100 $\mathrm{nM})$, or the combination of pemetrexed $(100 \mathrm{nM})$ and cisplatin $(10 \mu \mathrm{M})$ in growth media for varying exposure times ranging up to 48 hours. Whole cell lysates were then generated using a $1 \%$ Nonidet P-40 lysis buffer (Sigma-Aldrich Corp., St. Louis, MO). The suspension was homogenized by passages through a 20 -gauge syringe needle and nuclear material removed through centrifugation at $14000 \mathrm{rpm}$ for $15 \mathrm{~min}$ at $4^{\circ} \mathrm{C}$. Cell lysates were then loaded onto a precast Nupage Bis-Tris Gels (invitrogen, Life Technologies, Corp., Grand Island, NY) for electrophoresis then transferred onto Hybond-P PVDF membranes (Sigma-Aldrich Corp., St. Louis, MO) for Western blot analysis. After blocking membranes with 5\% non-fat milk in PBS with $0.1 \%$ Tween-20 buffer, PVDF membranes were probed using primary antibodies directed against human TK1 (Cell Signaling Technology, Danvers, MA; 1:5000), human TS (Cell Signaling Technology; 1:4000), or human $\beta$-actin (Sigma-Aldrich Corp., St. Louis, MO; 1:10000). Membrane were then washed and incubated (1:3000) with species-specific secondary antibodies, either anti-rabbit or anti-mouse, conjugated to horseradish peroxidase (GE Healthcare Life Science; 1:3000) for 1 hour, the proteins were detected using the Immobilon ECL system (EMD Millipore, Billerica, MA) and quantified using Image $\mathbf{J}$ software available through the National Institutes of Health (https://imagej.nih.gov/ ij/index.html).

\section{PET imaging}

Baseline FLT-PET scans were performed on the day prior to therapy. Mice were then treated with either the vehicle control (i.p. sterile PBS) or combination therapy with pemetrexed (i.p. $100 \mathrm{mg} / \mathrm{kg}$ ) and cisplatin $(10 \mathrm{mg} /$ $\mathrm{kg}$ ). A post-therapy FLT-PET was then performed at varying time points following administration of therapy.

For the assessment tumor response to therapy, tumor-bearing animals were treated for a period of two weeks with $100 \mathrm{mg} / \mathrm{kg}$ pemetrexed (i.p. daily; days 1-5 and 8-12) and $10 \mathrm{mg} / \mathrm{kg}$ cisplatin (i.p. once weekly). During this treatment period, tumor volumes were estimated by external caliper measurements. After therapy/ imaging completion, mice were euthanized with carbon dioxide inhalation.

After anesthesia with inhaled isofluorane in $\mathrm{O}_{2}$ (3\% induction, $1.5 \%$ maintenance), mice were injected intravenously with 300-350 $\mu \mathrm{Ci}$ of [18F]FLT then allowed to ${ }^{\prime \prime}$ "ecover from the anesthesia during the 60-min uptake time allowed for radiotracer accumulation. At 60 min postinjection, mice were anesthetized and imaged for a $15-$ min static acquisition on the small animal PET scanner (A-PET, built in collaboration with Philips Medical Systems) located at the University of Pennsylvania Small Animal Imaging Facility.

\section{CONFLICTS OF INTEREST}

The authors declare no potential conflicts of interest.

\section{FUNDING}

Department of Defense, Lung Cancer Research Program, Career Development Award, LC130313.

\section{REFERENCES}

1. Kenny LM, Contractor KB, Stebbing J, Al-Nahhas A, Palmieri C, Shousha S, Coombes RC, Aboagye EO. Altered tissue 3'-deoxy-3'-[18F]fluorothymidine pharmacokinetics in human breast cancer following capecitabine treatment detected by positron emission tomography. Clin Cancer Res. 2009; 15:6649-6657.

2. Lee SJ, Kim SY, Chung JH, Oh SJ, Ryu JS, Hong YS, Kim TW, Moon DH. Induction of thymidine kinase 1 after 5-fluorouracil as a mechanism for 3'-deoxy-3'[18F]fluorothymidine flare. Biochem Pharmacol. 2010; 80:1528-1536.

3. Pressacco J, Mitrovski B, Erlichman C, Hedley DW. Effects of thymidylate synthase inhibition on thymidine kinase activity and nucleoside transporter expression. Cancer Res. 1995; 55:1505-1508.

4. Wells P, Aboagye E, Gunn RN, Osman S, Boddy AV, Taylor GA, Rafi I, Hughes AN, Calvert AH, Price PM, Newell DR. 2-[11C]thymidine positron emission tomography as an indicator of thymidylate synthase inhibition in patients treated with AG337. J Natl Cancer Inst. 2003; 95:675-682.

5. McHugh CI, Lawhorn-Crews JM, Modi D, Douglas KA, Jones SK, Mangner TJ, Collins JM, Shields AF. Effects of capecitabine treatment on the uptake of thymidine analogs using exploratory PET imaging agents: 18F-FAU, 18F-FMAU, and 18F-FLT. Cancer Imaging. 2016; 16:34.

6. Heskamp S, Heijmen L, Gerrits D, Molkenboer-Kuenen JD, Ter Voert EG, Heinzmann K, Honess DJ, Smith DM, Griffiths JR, Doblas S, Sinkus R, Laverman P, Oyen WJ, et al. Response monitoring with [18F]FLT PET and diffusion-weighted MRI after cytotoxic 5-FU treatment in 
an experimental rat model for colorectal liver metastases. Mol Imaging Biol. 2017; 19:540-549.

7. Chen X, Yang Y, Berger I, Khalid U, Patel A, Cai J, Farwell MD, Langer C, Aggarwal C, Albelda SM, Katz SI. Early detection of pemetrexed-induced inhibition of thymidylate synthase in non-small cell lung cancer with FLT-PET imaging. Oncotarget. 2017; 8:24213-24223. https://doi. org/10.18632/oncotarget.12085.

8. Shields AF, Grierson JR, Dohmen BM, Machulla HJ, Stayanoff JC, Lawhorn-Crews JM, Obradovich JE, Muzik $\mathrm{O}$, Mangner TJ. Imaging proliferation in vivo with [F-18] FLT and positron emission tomography. Nat Med. 1998; 4:1334-1336.

9. Barthel H, Cleij MC, Collingridge DR, Hutchinson OC, Osman S, He Q, Luthra SK, Brady F, Price PM, Aboagye EO. 3'-deoxy-3'-[18F]fluorothymidine as a new marker for monitoring tumor response to antiproliferative therapy in vivo with positron emission tomography. Cancer Res. 2003; 63:3791-3798.

10. Muzi M, Vesselle H, Grierson JR, Mankoff DA, Schmidt RA, Peterson L, Wells JM, Krohn KA. Kinetic analysis of 3'-deoxy-3'-fluorothymidine PET studies: validation studies in patients with lung cancer. J Nucl Med. 2005; 46:274-282.

11. Rasey JS, Grierson JR, Wiens LW, Kolb PD, Schwartz JL. Validation of FLT uptake as a measure of thymidine kinase-1 activity in A549 carcinoma cells. J Nucl Med. 2002; 43:1210-1217.

12. Vesselle H, Grierson J, Muzi M, Pugsley JM, Schmidt RA, Rabinowitz P, Peterson LM, Vallieres E, Wood DE. In vivo validation of 3 'deoxy-3'-[(18)F]fluorothymidine ([(18)F]FLT) as a proliferation imaging tracer in humans: correlation of [(18)F]FLT uptake by positron emission tomography with Ki-67 immunohistochemistry and flow cytometry in human lung tumors. Clin Cancer Res. 2002; 8:3315-3323.

13. Paproski RJ, Wuest M, Jans HS, Graham K, Gati WP, McQuarrie S, McEwan A, Mercer J, Young JD, Cass CE. Biodistribution and uptake of 3'-deoxy-3'-fluorothymidine in ENT1-knockout mice and in an ENT1-knockdown tumor model. J Nucl Med. 2010; 51:1447-1455.

14. Paproski RJ, Ng AM, Yao SY, Graham K, Young JD, Cass $\mathrm{CE}$. The role of human nucleoside transporters in uptake of 3'-deoxy-3'-fluorothymidine. Mol Pharmacol. 2008; 74:1372-1380.

15. Plotnik DA, Emerick LE, Krohn KA, Unadkat JD, Schwartz JL. Different modes of transport for 3H-thymidine, 3H-FLT, and 3H-FMAU in proliferating and nonproliferating human tumor cells. J Nucl Med. 2010; 51:1464-1471.

16. Plotnik DA, McLaughlin LJ, Chan J, Redmayne-Titley JN, Schwartz JL. The role of nucleoside/nucleotide transport and metabolism in the uptake and retention of 3'-fluoro-3'deoxythymidine in human B-lymphoblast cells. Nucl Med Biol. 2011; 38:979-986.
17. Perumal M, Pillai RG, Barthel H, Leyton J, Latigo JR, Forster M, Mitchell F, Jackman AL, Aboagye EO. Redistribution of nucleoside transporters to the cell membrane provides a novel approach for imaging thymidylate synthase inhibition by positron emission tomography. Cancer Res. 2006; 66:8558-8564.

18. Pillai RG, Forster M, Perumal M, Mitchell F, Leyton J, Aibgirhio FI, Golovko O, Jackman AL, Aboagye EO. Imaging pharmacodynamics of the alpha-folate receptortargeted thymidylate synthase inhibitor BGC 945. Cancer Res. 2008; 68:3827-3834.

19. Plotnik DA, McLaughlin LJ, Krohn KA, Schwartz JL. The effects of 5-fluoruracil treatment on 3'-fluoro-3'deoxythymidine (FLT) transport and metabolism in proliferating and non-proliferating cultures of human tumor cells. Nucl Med Biol. 2012; 39:970-976.

20. Frings V, van der Veldt AA, Boellaard R, Herder GJ, Giovannetti E, Honeywell R, Peters GJ, Thunnissen E, Hoekstra OS, Smit EF. Pemetrexed induced thymidylate synthase inhibition in non-small cell lung cancer patients: a pilot study with 3 '-deoxy-3'-[(1)(8)F]fluorothymidine positron emission tomography. PLoS One. 2013; 8:e63705.

21. Hong YS, Kim HO, Kim KP, Lee JL, Kim HJ, Lee SJ, Lee SJ, Oh SJ, Kim JS, Ryu JS, Moon DH, Kim TW. 3'-Deoxy3'-18F-fluorothymidine PET for the early prediction of response to leucovorin, 5-fluorouracil, and oxaliplatin therapy in patients with metastatic colorectal cancer. J Nucl Med. 2013; 54:1209-1216.

22. Takezawa K, Okamoto I, Okamoto W, Takeda M, Sakai K, Tsukioka S, Kuwata K, Yamaguchi H, Nishio K, Nakagawa $\mathrm{K}$. Thymidylate synthase as a determinant of pemetrexed sensitivity in non-small cell lung cancer. Br J Cancer. 2011; 104:1594-1601.

23. Sigmond J, Backus HH, Wouters D, Temmink OH, Jansen $\mathrm{G}$, Peters GJ. Induction of resistance to the multitargeted antifolate Pemetrexed (ALIMTA) in WiDr human colon cancer cells is associated with thymidylate synthase overexpression. Biochem Pharmacol. 2003; 66:431-438.

24. Saga Y, Suzuki M, Mizukami H, Kohno T, Takei Y, Fukushima M, Ozawa K. Overexpression of thymidylate synthase mediates desensitization for 5-fluorouracil of tumor cells. Int J Cancer. 2003; 106:324-326.

25. Copur S, Aiba K, Drake JC, Allegra CJ, Chu E. Thymidylate synthase gene amplification in human colon cancer cell lines resistant to 5-fluorouracil. Biochem Pharmacol. 1995; 49:1419-1426.

26. Patki M, Gadgeel S, Huang Y, McFall T, Shields AF, Matherly LH, Bepler G, Ratnam M. Glucocorticoid receptor status is a principal determinant of variability in the sensitivity of non-small-cell lung cancer cells to pemetrexed. J Thorac Oncol. 2014; 9:519-526. 